\title{
Investigation into rail corrugation in high-speed railway tracks from the viewpoint of the frictional self-excited vibration of a wheel-rail system
}

\author{
G. X. Chen ${ }^{1}$ X. L. Cui ${ }^{1}$ W. J. Qian ${ }^{1}$
}

Received: 12 October 2015/Revised: 11 April 2016/Accepted: 12 April 2016/Published online: 30 April 2016

(C) The Author(s) 2016. This article is published with open access at Springerlink.com

\begin{abstract}
A finite element vibration model of a multiple wheel-rail system which consists of four wheels, one rail, and a series of sleepers is established to address the problem of rail corrugation in high-speed tracks. In the model, the creep forces between the wheels and rail are considered to be saturated and equal to the normal contact forces times the friction coefficient. The oscillation of the rail is coupled with that of wheels in the action of the saturated creep forces. When the coupling is strong, selfexcited oscillation of the wheel-rail system occurs. The self-excited vibration propensity of the model is analyzed using the complex eigenvalue method. Results show that there are strong propensities of unstable self-excited vibrations whose frequencies are less than $1,200 \mathrm{~Hz}$ under some conditions. Preventing wheels from slipping on rails is an effective method for suppressing rail corrugation in high-speed tracks.
\end{abstract}

Keywords Rail corrugation - Wear · Friction-induced vibration - Self-excited vibration - Elastic vibration mode . Wheel-rail system $\cdot$ High-speed railway

\section{Introduction}

The total mileage of Chinese high-speed railway has exceeded 16,000 km since the Beijing-Tianjin high-speed intercity railway line with an overall length of $120 \mathrm{~km}$ was

G. X. Chen

chen_guangx@163.com

1 State Key Laboratory of Traction Power, Tribology Research Institute, Southwest Jiaotong University, Chengdu 610031, China put into operation in 2008. With the operation speed of high-speed trains arriving at $300-350 \mathrm{~km} / \mathrm{h}$, the operation safety of trains has become a main concern to the railway administrators and passengers. Rail corrugation and polygonalization of high-speed railway wheels are two emergent problems influencing the operation safety and comfort of trains in the Chinese high-speed railway industry. For instance, the Beijing-Shanghai high-speed railway line has an overall length of $1,318 \mathrm{~km}$, and was first put into operation in 2011. After 2-3 months' operation, rail corrugation occurred in some track sections. Polygonalization of high-speed railway wheels was also found to be serious after the high-speed trains were used for 1-2 years. Rail corrugation and polygonalization of high-speed railway wheels can not only lead to a poor passenger ride comfort and a high environment noise level but also decrease the service life of some key parts such as wheelsets, bearings, and rails. Therefore, it is significant to study the rail corrugation and polygonalization of highspeed railway wheels in high-speed railway lines. This paper mainly concerns the problem of rail corrugation.

Rail corrugation is an undulatory wear which occasionally occurs on the rail rolling surface. The research history of rail corrugation can be traced back to 1900s. Since then, many researchers have made gigantic contributions to the understanding of the generation mechanism of rail corrugation. It is well known that the generation mechanism of rail corrugation consists of both the material damage and wavelength fixing mechanisms [1]. Several sagacious concepts have been proposed in the literature, which include the wear law of the frictional power causing rail working surface wear [2], the feedback mechanism for corrugation development [3], the contact filter [4], the pinned-pinned resonance [5], and so on. Specifically, Hempelmann et al. [2] studied rail corrugation, holding an 
opinion that rail working surface wear is dominated by the wear law of the frictional power. Hempelmann and Knothe [3] extended a linear model to study the short pitch corrugation. Müller [6] studied rail corrugation from the instability of the wheel-rail system. Igeland and Ilias [7] studied rail corrugation from the viewpoint of non-linear interaction between wheel and rail. Knothe and Ripke [8] studied parameter sensitivity of rail corrugation. Andersson and Johansson [9] studied rail corrugation using a threedimensional wheel-rail interaction model. Johansson and Nielsen [10] studied the influence of powered wheelsets with wheel tread irregularities on rail corrugation. Clark [11] and Brockley [12] studied rail corrugation from the viewpoint of stick-slip vibration of the wheel-rail system. $\mathrm{Wu}$ and Thompson [13] attributed rail corrugation to the micro-slip between wheel and rail. Xie and Iwnicki [14] analyzed the railhead wear using a three-dimensional nonHertzian and non-steady contact model. Daniel and Coworkers [15] discussed the effect of the wheel pass time delay on rail corrugation. Matsumoto [16] and Suda [17] all believed that rail corrugation was probably due to the stick-slip vibration of the wheel-rail system. Sun and Simson [18] studied rail corrugation using an integrated model including rail surface roughness and stick-slip vibration of the wheel-rail system. Jin [19] developed a comprehensive three-dimensional train-track model to study rail corrugation. Contributions from these researchers constitute the theoretical groundwork of rail corrugation.

As concluded by Grassie [20], wear is a main material damage mechanism of rail corrugation. Most of the above investigations on rail corrugation were focused on the wavelength fixing mechanism. Research [1, 21, 22] shows that the wavelength fixing mechanism includes the P2 resonance of the interaction between wheel and rail, the pinned-pinned resonance of tracks, the second torsional resonance of driven axles, and the transient dynamic interaction between wheel and rail due to initial rail surface roughness. Among these proposed mechanisms, the transient dynamic interaction between wheel and rail is widely accepted. Now, most simulation works on rail corrugation are all based on this mechanism.

However, it should be noted that the existing rail corrugation knowledge cannot lead to a good solution to rail corrugation other than rail grinding. Rail corrugation is severer than ever before. In Chinese metro tracks, almost all tracks whose curve radii are less than $350 \mathrm{~m}$ suffer from rail corrugation. Rail corrugation in high-speed railway lines and polygonalization of high-speed railway wheels are puzzling the high-speed railway industry. We cannot predict where rail corrugation will occur in the design stage of a high-speed railway line. We know that rail corrugation is inevitable in tight curved tracks, but it is strange that most rail corrugations usually occur on the low rail and seldom occur on the high rail although there is no apparent difference between the receptances of the low and the high rails. To date, it appears that a satisfactory and objective explanation to the reason why most rail corrugations occur on the low rail of tight curved tracks cannot be available in the literature.

Severe and uncontrolled rail corrugation suggests that there is still a need to study rail corrugation from a new perspective. Recently, the authors proposed the viewpoint that rail corrugation is caused by friction-induced vibration of the wheel-rail system [23]. At the same time, Kurzeck and Hecht [24] also proposed the similar viewpoint based on a simple model with 3 degrees of freedom. In their works, the material damage mechanism is wear and the wavelength fixing mechanism is the friction-induced self-excited vibration of the wheel-rail system. Different from the second torsional resonance of driven axles, the saturated creep forceinduced mode coupling between wheel and rail leads to selfexcited vibration of the wheel-rail system to create corrugation. From the new insight of friction-induced vibration causing rail corrugation, one can objectively explain many rail corrugation phenomena such as most rail corrugations occurring on the low rail of tight curved tracks and little rail corrugation occurring in the curved track whose radius is larger than 600-700 $\mathrm{m}[25,26]$.

In this paper, rail corrugation in high-speed tracks is studied from the viewpoint of self-excited vibration of the wheel-rail system causing corrugation. An elastic vibration model of a multiple wheel-rail system is established for a vehicle traveling on a high-speed track. It is found that when the traction force or brake force is not well controlled, the slip friction between the wheel and rail can lead to self-excited vibration of the wheel-rail system to create rail corrugation.

\section{Self-excited vibration model of a multiple wheel-rail system}

\subsection{Rail corrugation phenomena in high-speed railway lines}

Figure 1 shows a picture of rail corrugation in a high-speed track [27]. Based on field investigations of rail corrugation in high-speed tracks, the following corrugation phenomena are found: (1) Rail corrugation in high-speed tracks most probably occurs in curved tracks, and the smaller the curve radius, the more easily rail corrugation takes place. (2) There is an apparent difference between the rail corrugation occurrence propensities in the train-up and train-down directions. In one direction, train brake is applied and in the other direction, no train brake is applied. Rail corrugation most probably occurs in track sections where trains are braked. 


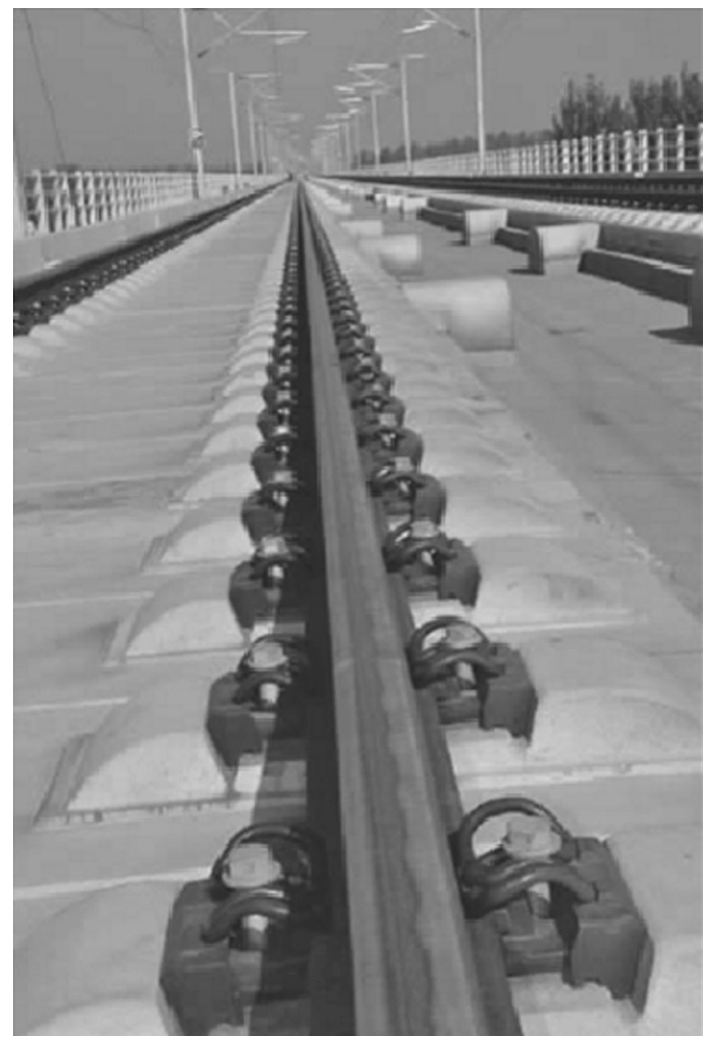

Fig. 1 Rail corrugation in a high-speed track [27]

\subsection{Contact and friction forces acting on a wheel}

The minimum radius of curved tracks in high-speed railway lines is larger than 7,000 m. According to the authors' investigation, rail corrugation seldom occurs in metro tracks whose radii are larger than 600-700 m. As mentioned above, rail corrugation in high-speed tracks most probably arises in the train brake section of tracks. Since rails are exposed to rain, snow, and dust, the friction coefficient between the wheel and rail is changed in a large range. Based on these facts, the authors can reasonably assume that the wheels slip on the rail in some brake applications. In the present paper, the self-excited vibration model of the wheel-rail system is based on this assumption. Wheels are generally always kept in contact with the rail when a vehicle travels on a track. According to the vehicle system dynamics, the contact points between the wheels and rail on a tangential track fall in the central area of the rail top surface. The corresponding contact angles are in the range of about $1-3^{\circ}$. The interaction forces between the wheels and rail in this case is shown in Fig. 2 . The friction forces between the wheels and rail are along the direction of rail. In Fig. 2, $\delta$ is the contact angle; $N$ is the normal force; $F_{\mathrm{L}}$ is the lateral creep force; $w$ is the vertical suspension force applied by the axle box; $K_{\mathrm{RV}}$ and $K_{\mathrm{RL}}$ are vertical stiffness and lateral stiffness of the rail

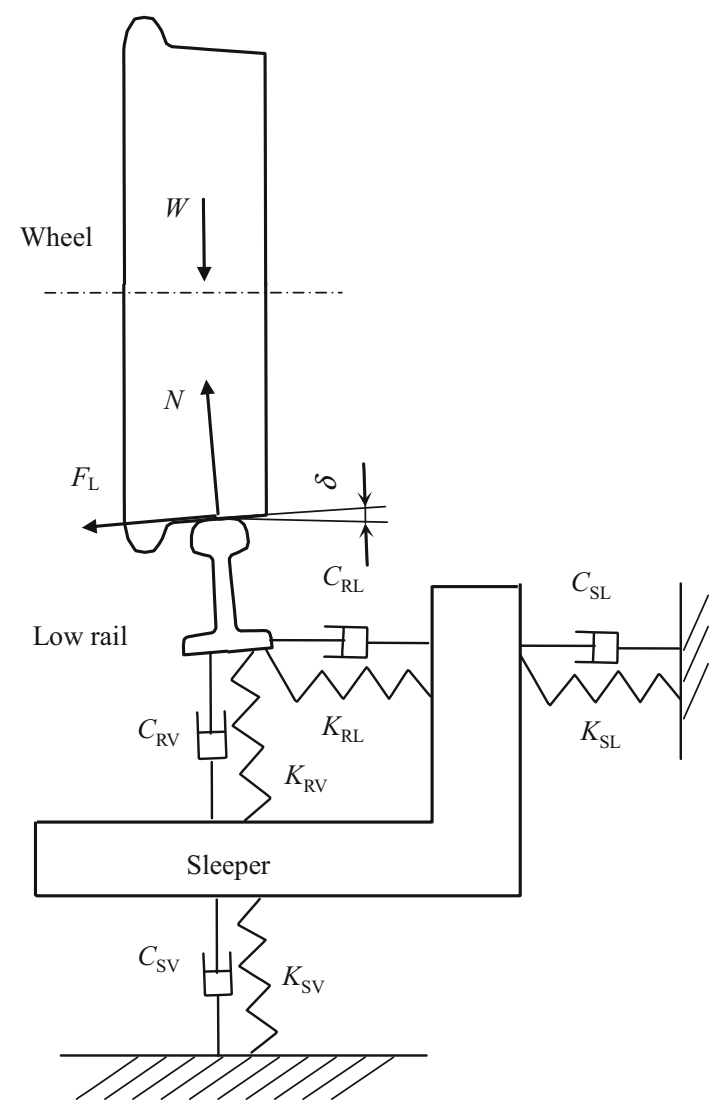

Fig. 2 Position of the contact point between four wheels and rail

fastener spring, respectively; $C_{\mathrm{RV}}$ and $C_{\mathrm{RL}}$ are vertical and lateral damping coefficients of the rail fastener dampers, respectively; $K_{\mathrm{SV}}$ and $K_{\mathrm{SL}}$ are vertical and lateral stiffness of the sleeper support springs, respectively; and, $C_{\mathrm{SV}}$ and $C_{\mathrm{SL}}$ are vertical and lateral damping coefficients of the sleeper support dampers, respectively.

\subsection{Finite element oscillation equations of the multiple wheel-rail system}

In the present work, the wheel-rail system consists of four wheels, one rail, and a series of sleepers. The creep force between the wheels and rail is considered to be saturated and is approximately equal to the normal force times the coefficient of friction. In the finite element oscillation equations, the friction coupling between the wheel and rail vibrations is very important for the occurrence of self-excited oscillation of the multiple wheel-rail system. The friction force is expressed as follows:

$F_{\mathrm{wr}, i}=-F_{\mathrm{rw}, i}=\mu k\left(u_{\mathrm{w}, i}-u_{\mathrm{r}, i}\right)$,

where $F_{\mathrm{wr}, i}$ and $F_{\mathrm{rw}, i}$ are the friction force components acting on the $i$ th node of the wheel and its corresponding $i$ th node of the rail, respectively; $\mu$ is the coefficient of friction; $k$ is the contact stiffness between the wheel and 
rail; and, $u_{\mathrm{w}, i}$ and $u_{\mathrm{r}, i}$ are the displacements of the $i$ th contact points of the wheel and rail in the normal direction, respectively. All components of the friction forces on the contact surfaces can be written in matrix form as follows:

$\boldsymbol{F}_{\mathrm{ff}}=\boldsymbol{K}_{\mathrm{ff}} \boldsymbol{u}$,

where $\boldsymbol{F}_{\mathrm{ff}}$ is the friction force vector of all the contact nodes, $\boldsymbol{K}_{\mathrm{ff}}$ is the contact stiffness matrix, and $\boldsymbol{u}$ is the displacement vector of all nodes of the multiple wheel-rail system. In the absence of friction between the sliding surfaces, the motion equations of the wheel-rail system are written as follows:

$\boldsymbol{M} \ddot{\boldsymbol{u}}+\boldsymbol{C} \dot{\boldsymbol{u}}+\boldsymbol{K u}=\mathbf{0}$,

where $\boldsymbol{M}, \boldsymbol{C}$, and $\boldsymbol{K}$ are respectively the mass, damping and stiffness matrixes of the system; and they are all symmetric matrices. Equation (3) is a stable system. In the presence of friction, the friction coupling between the wheels and rail cannot be ignored. The motion equations of the wheel-rail system with friction coupling are rewritten as follows:

$\boldsymbol{M} \ddot{\boldsymbol{u}}+\boldsymbol{C} \dot{\boldsymbol{u}}+\left(\boldsymbol{K}-\boldsymbol{K}_{\mathrm{ff}}\right) u=\mathbf{0}$.

The eigenvalue equation of Eq. (4) is

$\left(\boldsymbol{M} \lambda^{2}+\lambda \boldsymbol{C}+\left(\boldsymbol{K}-\boldsymbol{K}_{\mathrm{ff}}\right)\right) \boldsymbol{\varphi}=\mathbf{0}$,

where $\lambda$ is the eigenvalue, and $\varphi$ is the eigenvector.

The general solution of Eq. (4) is

$\boldsymbol{u}(t)=\sum \boldsymbol{\varphi}_{i} \exp \left(\lambda_{i} t\right)=\sum \boldsymbol{\varphi}_{i} \exp \left(\left(\alpha_{i}+\mathrm{j} \omega_{i}\right) t\right)$,

where $t$ is time; $\boldsymbol{\varphi}_{i}$ is the $i$ th eigenvector of Eq. (5); $\lambda_{i}=\alpha_{i}+\mathrm{j} \omega_{i}$ is the $i$ th eigenvalue of Eq. (5), in which $\alpha_{i}$ and $\omega_{i}$ are the real and imaginary parts of the $i$ th eigenvalue, and $\mathrm{j}$ is the imaginary unit. From Eq. (6), one can see that when a real part of eigenvalues is larger than zero, the displacement will increase with time, and the vibration displacements of the wheel-rail system will become larger and larger. In this case, the wheel-rail system becomes an unstable system. The self-excited vibration governing equations of frictional systems are composed of Eqs. (1-6). Generally, there are more than one million displacement degrees of freedom in a multiple wheel-rail system. A simulation analysis of the self-excited vibration of such a frictional system needs a high-efficient computer and consumes much computational time. More recently, the self-excited vibration theory of frictional systems has been accepted generally. Both ABAQUS and ANSYS finite element software packages provide a capability of analyzing the motion stability and transient dynamics of frictional systems [28]. The procedures of applying ABAQUS to evaluate the self-excited vibration occurrence propensity of the wheel-rail system are presented as follows:
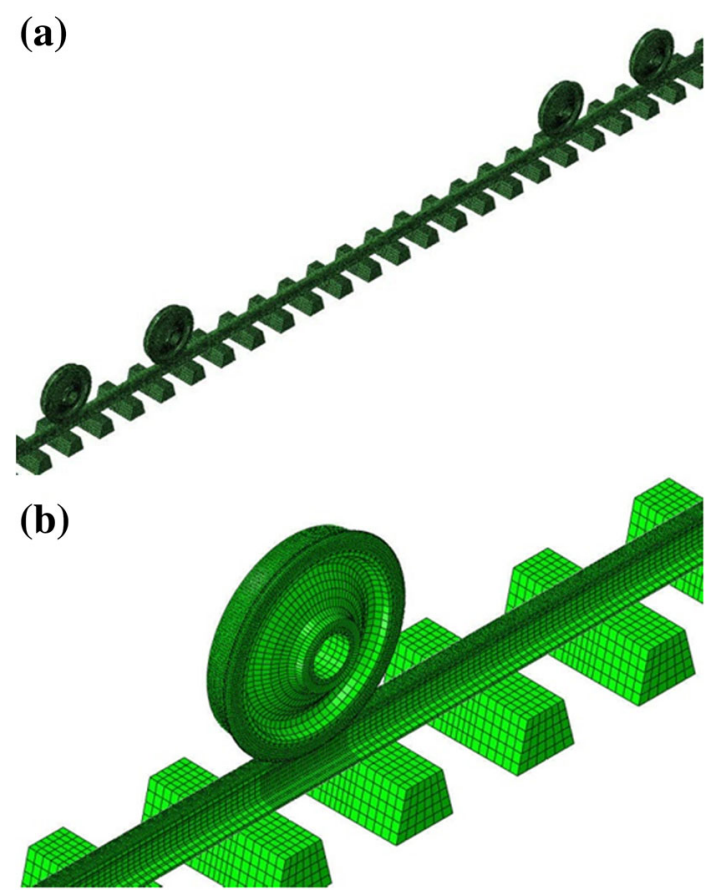

Fig. 3 Multiple wheel-rail model. a Overall layout. b Details

(1) Contact non-linear analysis to extract contact forces without friction.

(2) Contact non-linear analysis when the wheels are imposed to slide on the rail to extract contact forces with friction.

(3) Mode analysis to extract mode parameters when the friction coupling is ignored.

(4) Complex eigenvalue analysis to extract unstable mode parameters in the presence of friction coupling.

Figure 3 shows the finite element self-excited vibration model of the wheel-rail system. In the model, the rail is supported on a series of sleepers and the sleepers are supported on a monolithic track bed. The connections between the rail and sleepers and the connections between the sleepers and the monolithic track bed comprise a group of lateral springs and dampers, a group of vertical springs and dampers, and a group of longitudinal springs and dampers at each location of sleepers. The number of each group of springs and dampers between the rail and sleepers is the same as the number of the rail nodes on the contact area between the rail and each sleeper. The number of each group of springs and dampers between the sleepers and the monolithic track bed is the same as the number of the sleeper nodes on the contact area with the monolithic track bed.

Both the self-excited vibration of the wheel-rail system in the present paper and the traditional stick-slip vibration of the wheel-rail system fall into the category of the friction-induced vibration, but there is also some difference 
between them. The generation mechanism of the former vibration is attributed to the mode coupling induced by friction, while the latter vibration is attributed to the negative friction-speed slope. The feedback energy of the selfexcited vibration of the wheel-rail system is provided by the vibration displacement of the system, while the feedback energy of the traditional stick-slip vibration is provided by the vibration speed of the system.

\subsection{Nominal parameters of the wheel-rail system}

The Young's modulus of both the wheel and rail materials is $E=2.06 \times 10^{11} \mathrm{~N} / \mathrm{m}$. The density of the wheel and rail materials is $\rho=7,800 \mathrm{~kg} / \mathrm{m}^{3}$. The Poisson's ratio of both the wheel and rail materials is $v=0.3$. The contact angle is $\delta=2.5^{\circ}$. The vertical force applied on the wheel is $w=75,000 \mathrm{~N}$. The wheel is $840 \mathrm{~mm}$ in nominal diameter. The rail is the $60 \mathrm{~kg} / \mathrm{m}$ type, and $46,000 \mathrm{~mm}$ in length. The distance between two sleepers is $600 \mathrm{~mm}$. The width of sleepers is $160 \mathrm{~mm}$. The coefficient of friction between wheel and rail is $\mu=0.4$. In the present work, the lateral spring stiffness value $K_{\mathrm{RL}}$ of the rail fastener between the rail and each sleeper is assumed to be a half of the vertical spring stiffness value $K_{\mathrm{RV}}$; specifically $K_{\mathrm{RV}}=5.0 \times 10^{7} \mathrm{~N} / \mathrm{m}$, and $K_{\mathrm{RL}}=2.5 \times 10^{7} \mathrm{~N} / \mathrm{m}$. The vertical and lateral damping coefficients of each rail fastener are $C_{\mathrm{RV}}=5,000 \mathrm{Ns} / \mathrm{m}$ and $C_{\mathrm{RL}}=5,200 \mathrm{Ns} / \mathrm{m}$, respectively. The vertical and lateral spring stiffness values between each sleeper and the monolithic track bed are $K_{\mathrm{SV}}=8.9 \times 10^{7} \mathrm{~N} / \mathrm{m}$ and $K_{\mathrm{SL}}=5.0 \times$ $10^{7} \mathrm{~N} / \mathrm{m}$, respectively. The vertical and lateral damping values between each sleeper and the monolithic track bed are $C_{\mathrm{SV}}=8.98 \times 10^{4} \mathrm{Ns} / \mathrm{m}$ and $C_{\mathrm{SL}}=4.0 \times 10^{4} \mathrm{Ns} / \mathrm{m}$, respectively.

\section{Results}

\subsection{Unstable vibration characteristics of the wheel- rail system}

Rail corrugation is generally attributed to the vibration with a frequency in the range from 20 to $1,200 \mathrm{~Hz}$. Therefore, the simulation results are restricted to this frequency range. The effective damping ratio is a useful parameter for measuring the occurrence tendency of self-excited vibration. The larger the absolute value of the effective damping ratio, the more easily the corresponding vibration becomes unstable. The effective damping ratio is defined as $\zeta=-2 \operatorname{Re}(\lambda) /|\operatorname{Im}(\lambda)|$, where $\operatorname{Re}(\lambda)$ is the positive real part of the eigenvalue $\lambda$, and $|\operatorname{Im}(\lambda)|$ is the absolute value of the corresponding imaginary part of $\lambda$. Figure 4 demonstrates unstable vibration characteristics of the wheel-rail system in a frequency range from 20 to $1,200 \mathrm{~Hz}$. From this figure, we can see that in the prescribed frequency range, there are two unstable vibration modes, in which the wheel vibrates on the rail in the lateral direction. Since the effective damping ratio corresponding to the unstable vibration of $508.89 \mathrm{~Hz}$ is much larger than that corresponding to the unstable vibration of $331.44 \mathrm{~Hz}$, the unstable vibration of $508.89 \mathrm{~Hz}$ takes place more easily. It needs to be noted that the unstable vibration of $508.89 \mathrm{~Hz}$ is very close to the measured vibration frequency of corrugated rail, which is about $533.26 \mathrm{~Hz}$ [27].

\subsection{Influence of friction coefficient on rail corrugation}

Figure 5 demonstrates the change of the effective damping ratio of unstable vibration with the friction coefficient. From this figure, it is seen that when the friction coefficient between the wheels and rail is less than 0.28 , there is no unstable vibration, which suggests that no rail corrugation arises. We can also see that with the increasing of friction coefficient, the effective damping ratio is decreased, which suggests that rail corrugation takes place more easily in case of larger friction coefficient.
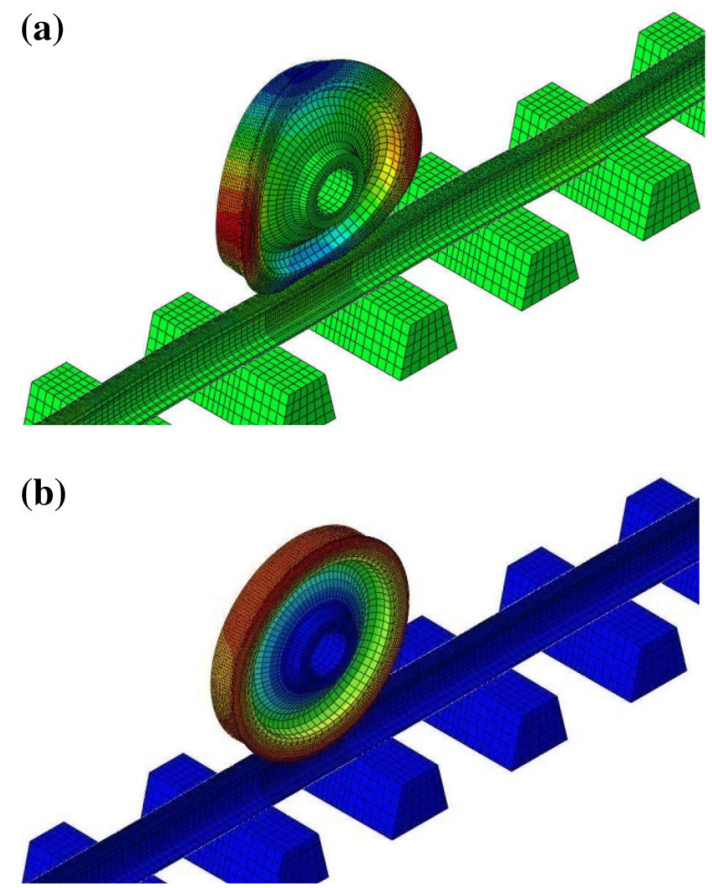

Fig. 4 Mode shapes of unstable vibrations of the wheel-rail system. a Unstable vibration frequency $f_{\mathrm{R}}=331.44 \mathrm{~Hz}$ and corresponding effective damping ratio $\xi=-0.001$. b $f_{\mathrm{R}}=508.89 \mathrm{~Hz}$ and $\xi=-0.0094$ 


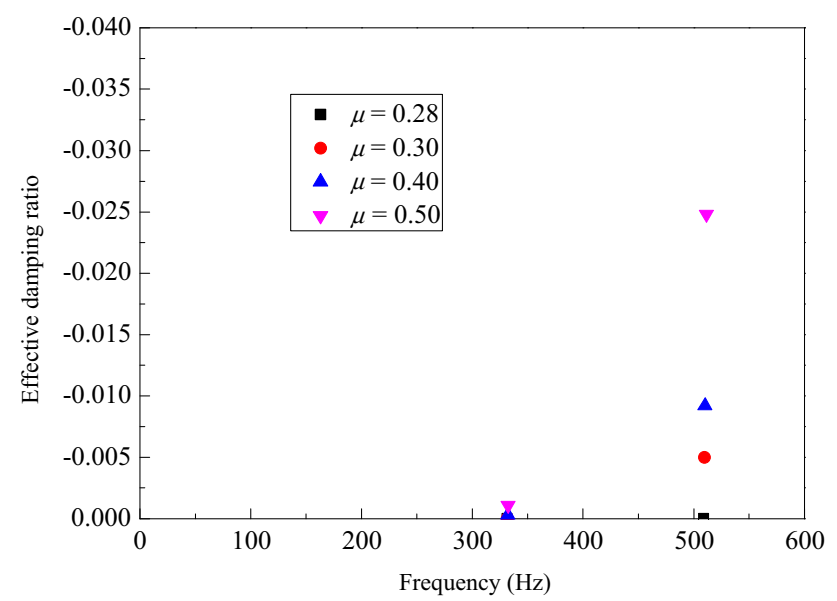

Fig. 5 Change of the effective damping ratio with the friction coefficient

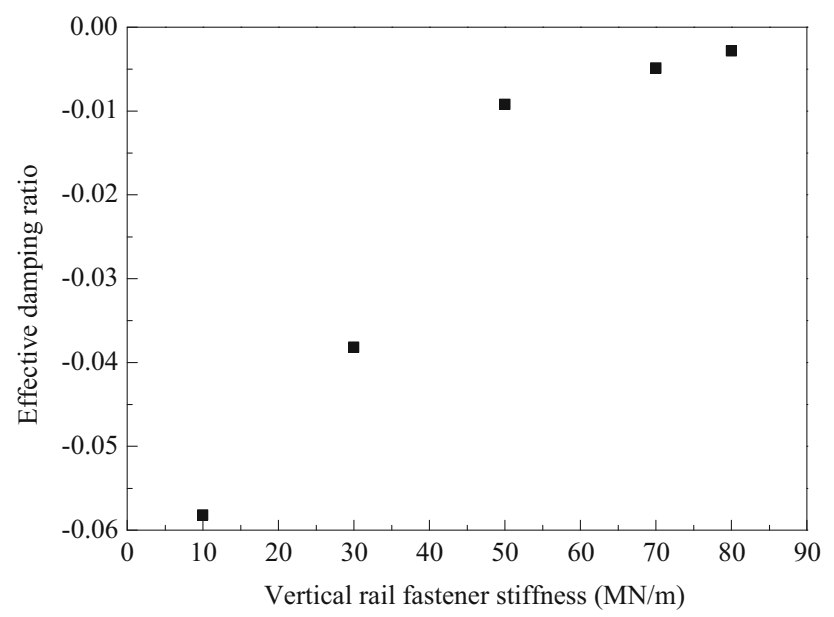

Fig. 6 Change of the effective damping ratio with the rail support stiffness. In the simulation, the lateral rail fastener stiffness is equal to a half of the vertical rail fastener stiffness

\subsection{Influence of rail fastener stiffness on rail corrugation}

Rail fastener stiffness is the connection stiffness between the rail and each sleeper. The rail is supported on sleepers by a series of rail fasteners. Figure 6 demonstrates the change of the effective damping ratio of unstable vibration with the vertical rail fastener stiffness. From Fig. 6, it is seen that with the decreasing of the vertical rail fastener stiffness, the effective damping ratio is decreased. Therefore, decreasing the vertical rail fastener stiffness will deteriorate rail corrugation.

In some cases, the lateral rail fastener stiffness is not equal to a half of the vertical rail fastener stiffness. Figure 7 shows the change of the effective damping ratio with the lateral rail fastener stiffness. We can see that the

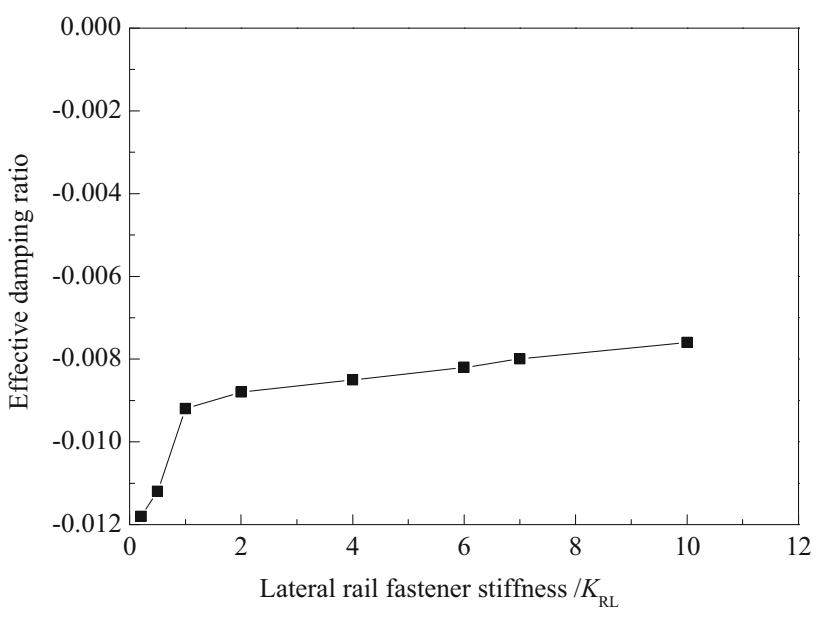

Fig. 7 Change of the effective damping ratio with lateral rail fastener stiffness, $K_{\mathrm{RV}}=5.0 \times 10^{7} \mathrm{~N} / \mathrm{m}$

effective damping ratio increases with the lateral rail fastener stiffness but the magnitude of change is small when the lateral rail fastener stiffness is in the range of $(0.2-10) K_{\mathrm{RL}}$.

\subsection{Influence of rail fastener damping on rail corrugation}

Now we study the influence of rail fastener damping on rail corrugation from the viewpoint of self-excited vibration of the wheel-rail system. Figure 8 shows the change of the effective damping ratio of the wheel-rail system with the rail fastener damping. As can be observed, when the rail fastener damping coefficient is six times the nominal rail fastener damping coefficient $C_{\mathrm{RV}}$, the absolute value of the effective damping ratio achieves its minimum value, which suggests that the rail corrugation can be suppressed as largely as possible in this case. When the rail fastener

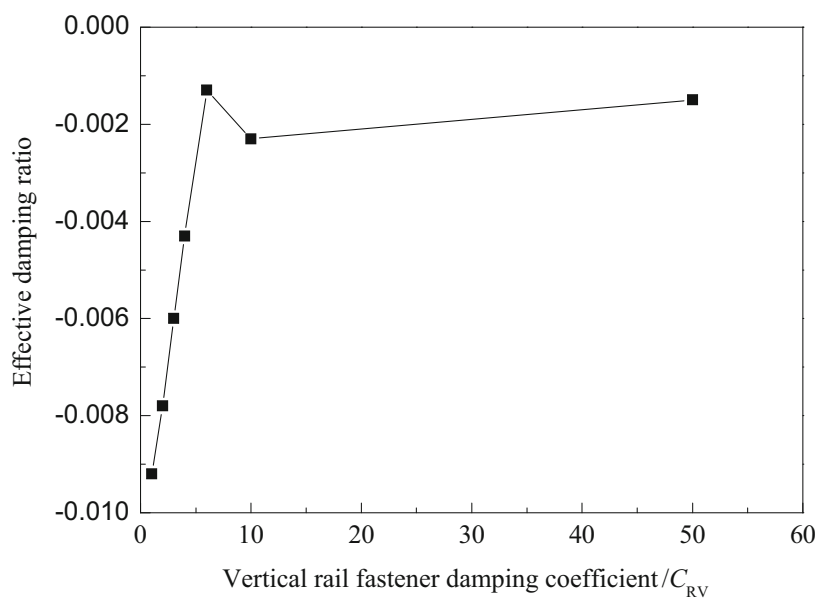

Fig. 8 Change of the effective damping ratio with the rail fastener damping, $C_{\mathrm{RL}}=5,200 \mathrm{Ns} / \mathrm{m}$ 


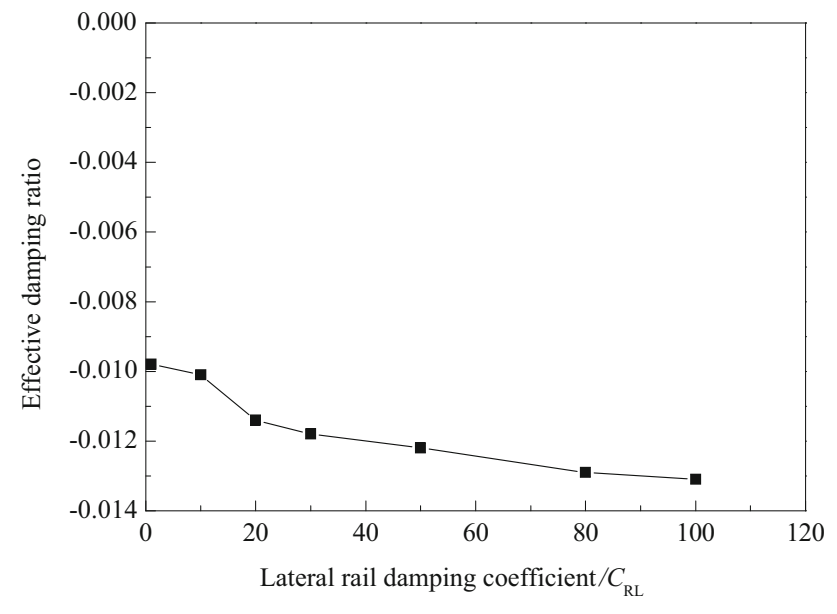

Fig. 9 Change of the effective damping ratio with the lateral rail fastener damping, $C_{\mathrm{RV}}=5,000 \mathrm{Ns} / \mathrm{m}$

damping coefficient increase to $10-50$ times the nominal rail fastener damping coefficient $C_{\mathrm{RV}}$, the effective damping ratio is close to each other, implying that a larger vertical rail fastener damping coefficient can alleviate rail corrugation.

Figure 9 shows the change of the effective damping ratio with the lateral rail fastener damping coefficient. It is found that when the lateral rail fastener damping coefficient is in the range of $1-100$ times the nominal lateral rail fastener damping coefficient $C_{\mathrm{RL}}$, the effective damping ratio only has a small change, implying that the lateral rail fastener damping coefficient has a little influence on rail corrugation.

\section{Discussion}

From the above simulation results, it is found that when wheels slip on the rail and the friction coefficient between the wheel and rail is large enough, unstable vibration of the wheel-rail system will occur, signifying that rail corrugation will arise. Therefore, the effective method for controlling and suppressing rail corrugation in high-speed tracks is to prevent wheels slipping on rails. If the wheel does not slip on the rail, self-excited vibration of the wheel-rail system will not take place. Thus, rail corrugation will not occur. The present result explains why rail corrugation most probably takes place in train brake sections of tracks. This is because the wheel is easy to slip on the rail due to a low coefficient of friction when a train is braked at a high speed. This result can also be used to explain why most of rails in high-speed tracks are not subjected to corrugation, where wheel slipping on rail rarely takes place.

\section{Conclusions}

In this paper, a numerical study on rail corrugation in highspeed railway lines is performed from the viewpoint of friction-induced self-excited vibration causing rail corrugation. The following conclusions can be drawn.

(1) When a wheel slip on a rail, the friction force can induce unstable vibration of the wheel-rail system. This unstable vibration leads to rail corrugation. Numerical simulation reveals that unstable vibration of frequency $508.89 \mathrm{~Hz}$ most probably takes place.

(2) Preventing wheels from slipping on rails is an effective method for suppressing rail corrugation.

(3) With vertical rail fastener stiffness increasing, the occurrence propensity of rail corrugation will decrease.

Acknowledgments This work was supported by the National Natural Science Foundation of China (No. 51275429).

Open Access This article is distributed under the terms of the Creative Commons Attribution 4.0 International License (http:// creativecommons.org/licenses/by/4.0/), which permits unrestricted use, distribution, and reproduction in any medium, provided you give appropriate credit to the original author(s) and the source, provide a link to the Creative Commons license, and indicate if changes were made.

\section{References}

1. Grassie SL, Kalousek J (1993) Rail corrugation: characteristics, causes and treatments. J Rail Rapid Transit 207:57-68

2. Hempelmann K, Hiss F, Knothe K, Ripke B (1991) The formation of wear patterns on rail tread. Wear 144:179-195

3. Hempelmann K, Knothe K (1996) An extended linear model for the prediction of short pitch corrugation. Wear 191:161-169

4. Remington PJ (1976) Wheel/rail noise, parts I-IV. J Sound Vib 46:359-451

5. Hiensch M, Nielsen JCO, Verheijen E (2002) Rail corrugation in the Netherlands-measurements and simulations. Wear 253:140149

6. Müller S (1999) A linear wheel-track model to predict instability and short pitch corrugation. J Sound Vib 227:899-913

7. Igeland A, Ilias H (1997) Railhead corrugation growth predictions based on nonlinear high frequency vehicle/track interaction. Wear 213:90-97

8. Knothe K, Ripke B (1989) The effects of the parameters of wheelset, track and running conditions on the growth-rate of rail corrugations. Veh Syst Dyn 18:345-356

9. Andersson C, Johansson A (2004) Prediction of rail corrugation generated by three-dimensional wheel-rail interaction. Wear 257:423-434

10. Johansson A, Nielsen JCO (2007) Rail corrugation growth-influence of powered wheelsets with wheel tread irregularities. Wear 262:1296-1307

11. Clark RA (1984) Slip-stick vibrations may hold the key to corrugation puzzle. Railw Gaz Int 7:531-533 
12. Brockley CA (1988) An investigation of rail corrugation using friction-induced vibration theory. Wear 128:99-106

13. Wu TX, Thompson DJ (2005) An investigation into rail corrugation due to micro-slip under multiple wheel/rail interactions. Wear 258:1115-1125

14. Xie G, Iwnicki SD (2008) Calculation of wear on a corrugated rail using a three-dimensional contact model. Wear 265(9-10):12381248

15. Meehan PA, Daniel WJT, Campey T (2005) Prediction of the growth of wear-type rail corrugation. Wear 258:1001-1013

16. Matsumoto A, Sato Y et al (1996) Study on the formation mechanism of rail Corrugation on curved track. Veh Syst Dyn 25:450-465

17. Suda Y, Hanawa M, Okumura M, Iwasa T (2002) Study on rail corrugation in sharp curves of commuter line. Wear 253:193-198

18. Sun YQ, Simson S (2008) Wagon-track modeling and parametric study on rail corrugation initiation due to wheel stick-slip process on curved track. Wear 265:1193-1201

19. Jin XS, Wen ZF, Wang KY et al (2006) Three-dimensional traintrack model for study of rail corrugation. J Sound Vib 293: 830-855

20. Grassie SL (2005) Rail corrugation: advances in measurement, understanding, and treatment. Wear 258:1224-1234
21. Sato Y, Matsumoto A, Knothe K (2002) Review on rail corrugation studies. Wear 253:130-139

22. Oostermeijer KH (2008) Review on short pitch rail corrugation studies. Wear 265:1231-1237

23. Chen GX, Zhou ZR, Ouyang H et al (2010) A finite element study on rail corrugation based on saturated creep force-induced self-excited vibration of a wheelset-track system. J Sound Vib 329(22):4643-4655

24. Kurzeck B, Hecht M (2010) Dynamic simulation of friction-induced vibrations in a light railway bogie while curving compared with measurement results. Veh Syst Dyn 48(sup1):121-138

25. Qian WJ, Chen GX, Ouyang H et al (2014) A transient dynamic study of the self-excited vibration of a railway wheel set-track system induced by saturated creep forces. Veh Syst Dyn 52(9): $1115-1138$

26. Cui XL, Chen GX, Yang HG, Zhang Q, Ouyang H, Zhu MH (2015) Effect of the wheel/rail contact angle and the direction of the saturated creep force on rail corrugation. Wear 330-331:554-562

27. Wang LQ (2013) Research and control on railroad rail corrugation. Railw Constr Technol 12:101-117 (in Chinese)

28. Ouyang H, Nack W, Yuan Y, Chen F (2005) Numerical analysis of automotive disc brake squeal. Int J Veh Noise Vib 1:207-231 